Supplement of Earth Syst. Sci. Data, 12, 177-196, 2020

https://doi.org/10.5194/essd-12-177-2020-supplement

(C) Author(s) 2020. This work is distributed under

the Creative Commons Attribution 4.0 License.

(c) (1)

Supplement of

\title{
The global long-term microwave Vegetation Optical Depth Climate Archive (VODCA)
}

\section{Leander Moesinger et al.}

Correspondence to: Leander Moesinger (leander.moesinger@geo.tuwien.ac.at, vodca@geo.tuwien.ac.at)

The copyright of individual parts of the supplement might differ from the CC BY 4.0 License. 


\section{Description of data variables \& summary of flags}

Here all the variables in the netcdf files are described, as well as a short summary of all flags. Most of this information is also in the metadata.

- VOD: Unitless, Vegetation Optical Depth of the respective band

- sensor_flag: Bit-flag indicating which sensors contributed to each observation.

- 1 = AMSR-E

$-2=$ AMSR 2

$-3=\mathrm{SSM} / \mathrm{I} \mathrm{F} 8$

-4 = SSM/I F11

10

$-5=\mathrm{SSM} / \mathrm{I}$ F13

$-6=\mathrm{TMI}$

$-7=$ WindSat

_ processing_flag: Bit-flag indicating irregularities during processing affecting the quality of the VOD values

Table 1. Summary of all quality bit-flags indicating irregular processing. For more details see the referenced section. Currently only Cband VODCA is sometimes processed in a non standard way, for the $\mathrm{Ku}$ - and $\mathrm{X}$-band they are always zero, indicating that everything was processed in in the standard way

\begin{tabular}{|c|c|c|c|c|}
\hline Bit & Section & Short description & Potential spatial occurrence & Reduction of quality \\
\hline 10 & 3.1 & $\begin{array}{l}\text { AMSR-2 } 7.3 \mathrm{GHz} \text { band is } \\
\text { used instead of } 6.9 \mathrm{GHz}\end{array}$ & Global, usually high RFI areas & Very small \\
\hline 11 & 3.2.4 & $\begin{array}{l}\text { Sensor is scaled to matched } \\
\text { TMI instead of AMSR-E }\end{array}$ & $35^{\circ} \mathrm{S}-35^{\circ} \mathrm{N}$ & Small \\
\hline 12 & 3.2 .4 & $\begin{array}{l}\text { Sensor scaled without temporally } \\
\text { overlapping observations }\end{array}$ & Global, mostly outside $35^{\circ} \mathrm{S}-35^{\circ} \mathrm{N}$ & $\begin{array}{l}\text { Possibly very large if the years } \\
2010-2014 \text { were very irregular. }\end{array}$ \\
\hline
\end{tabular}

- time/lon/lat: Dimensions of the data. 


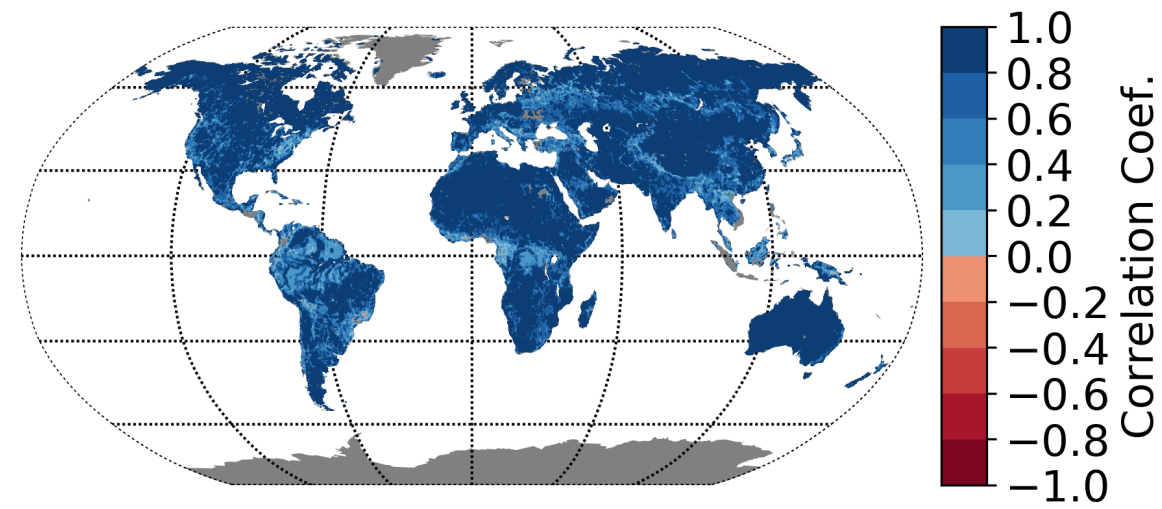

Figure 1. Correlation between the AMSR2 6.9 and $7.3 \mathrm{GHz}$ band

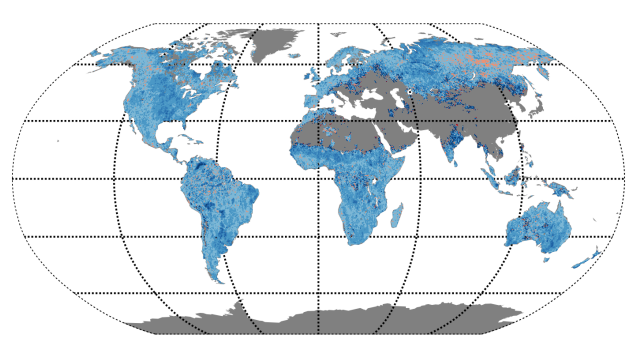

(a) L-band LPRM-SMAP vs. LPRM-SMOS

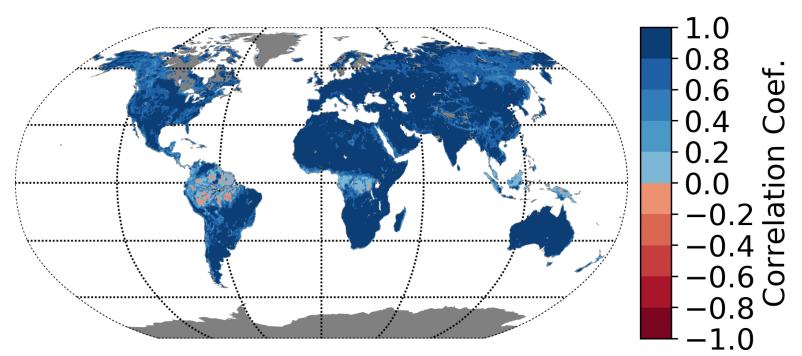

(b) Ku-band AMSR-E vs. WindSat

Figure 2. Correlations between different sensors of the same band. The Ku-band WindSat vs. AMSR-E plot is similar to all other sensor combinations in the $\mathrm{Ku}, \mathrm{X}$, and $\mathrm{C}$ band.

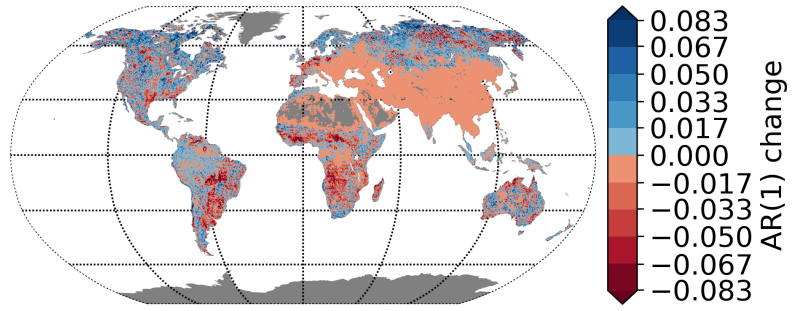

(a) SMAP

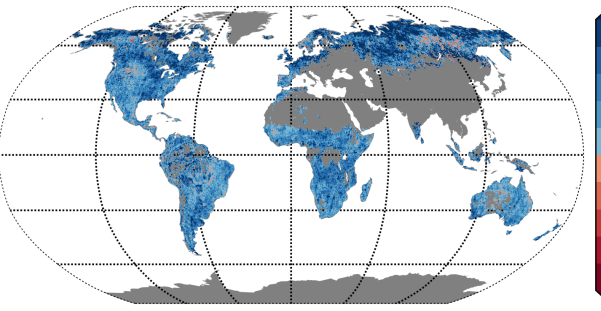

0.048

0.036

0.024

0.012

0.000 บ

$-0.012 \subsetneq$

-0.036 年

$-0.048$

(b) SMOS

Figure 3. First-order auto-correlation change due to experimental merging of L-band data for each sensor 


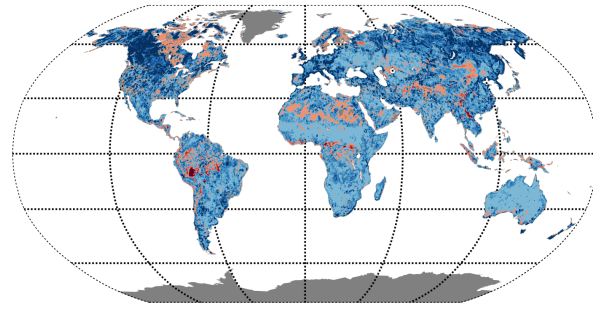

(a) AMSR-E

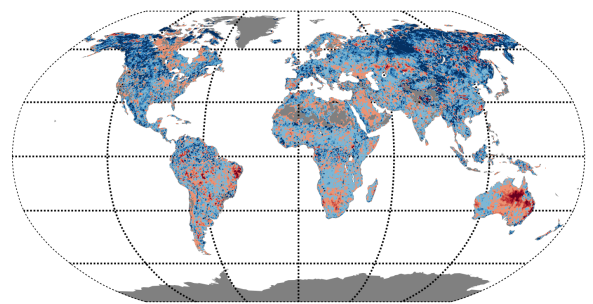

(c) AMSR2
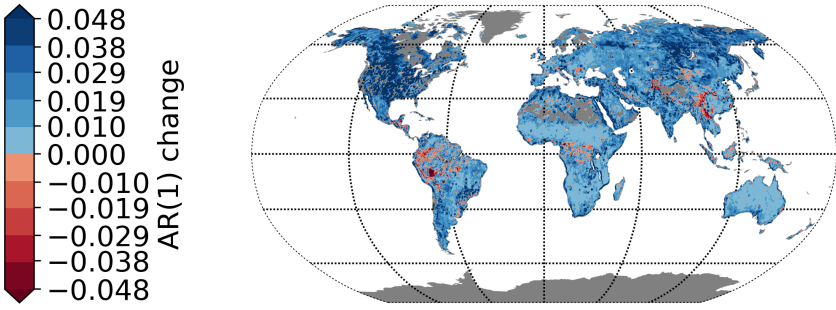

0.093 0.070 0.046 C 0.023 ป -0.023 $-0.046$ $-0.070<$ $-0.093$

$$
\begin{aligned}
& 0.0026 \\
& 0.0020 \\
& 0.0013 \\
& 0.0007 \\
& 0.0000 \\
& -0.0007 \\
& -0.0013 \\
& -0.0020 \\
& -0.0026 \\
& \hline
\end{aligned}
$$

(b) WindSat

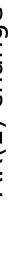

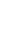




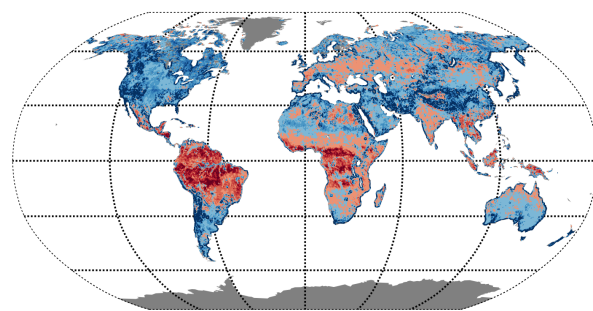

(a) AMSR-E

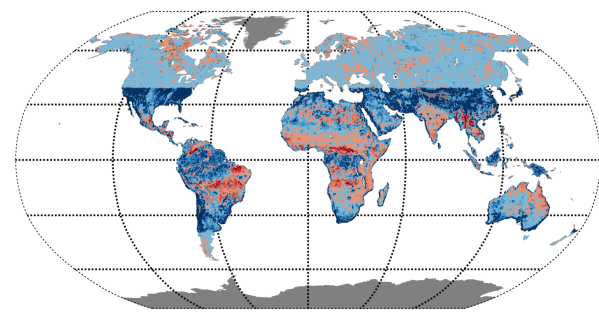

(c) AMSR2

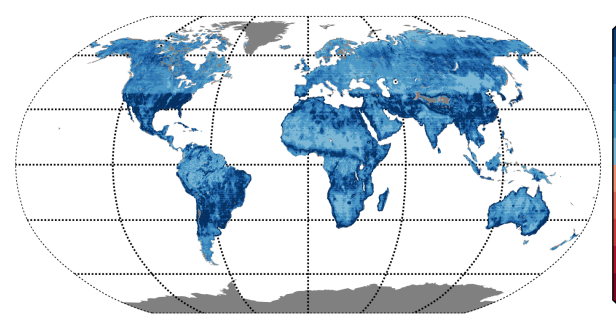

(e) $\mathrm{SSM} / \mathrm{I}$
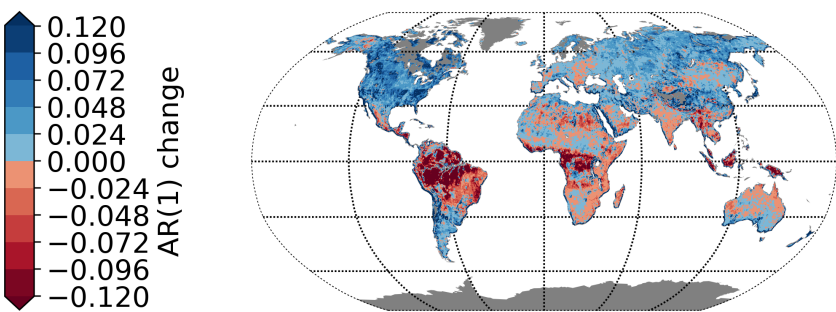

0.090

0.068

0.045

0.023

0.000 บ

-0.023 Э

$-0.045 \approx$

-0.068
-0.090

(b) WindSat
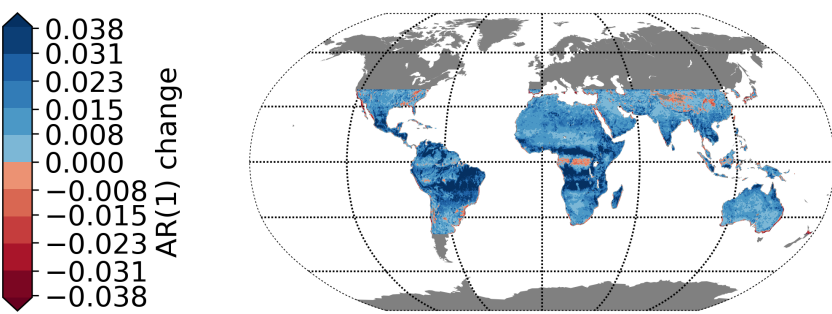

0.111

0.083

0.055

0.028

0.000 ป

-0.028 -

$-0.055 \%$

$-0.083<$

$-0.111$



(d) TMI

0.109

.

0.065

0

0.000

$-0.022$

-0.044 전

$-0.065$

$-0.109$

Figure 6. First-order auto-correlation change due to merging of Ku-band data for each sensor

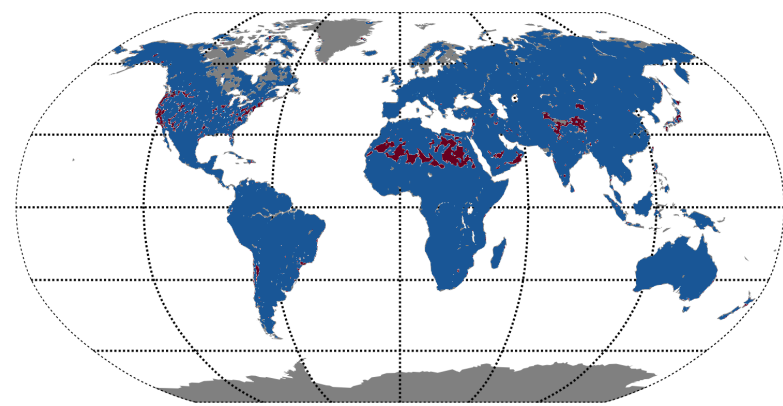

(a) WindSat

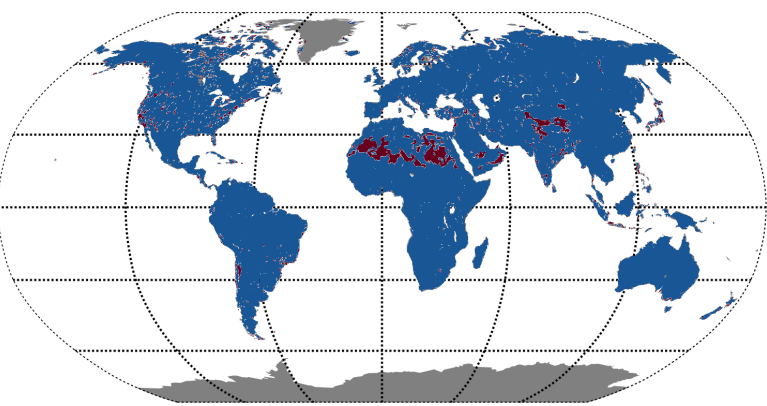

(b) AMSR2

Figure 7. C-band data loss due to failed CDF matching 


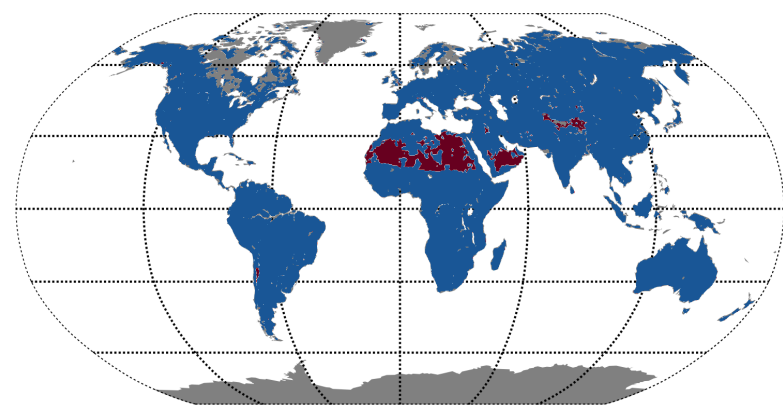

(a) WindSat

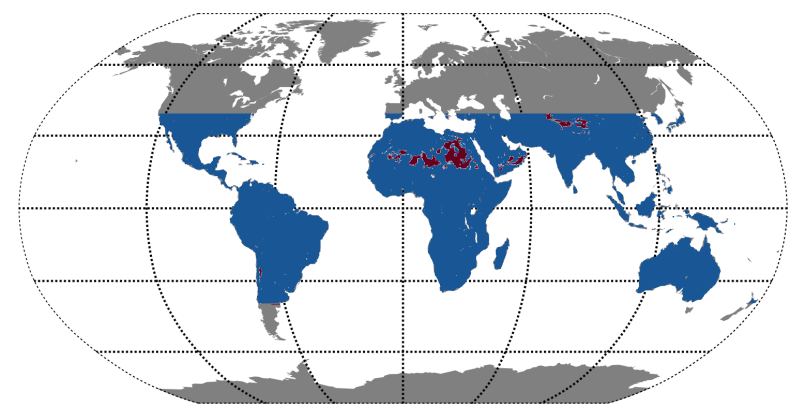

(c) TMI

Figure 8. X-band data loss due to failed CDF matching

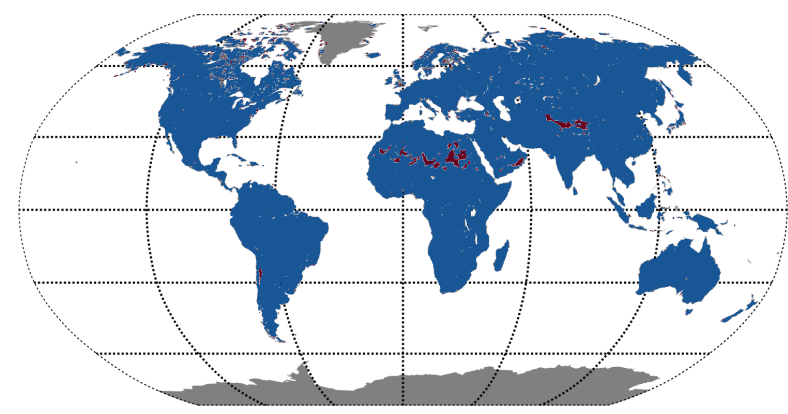

(b) AMSR2 


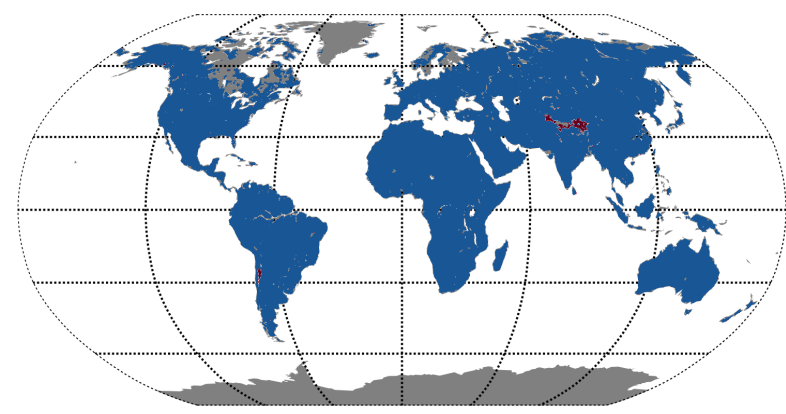

(a) WindSat

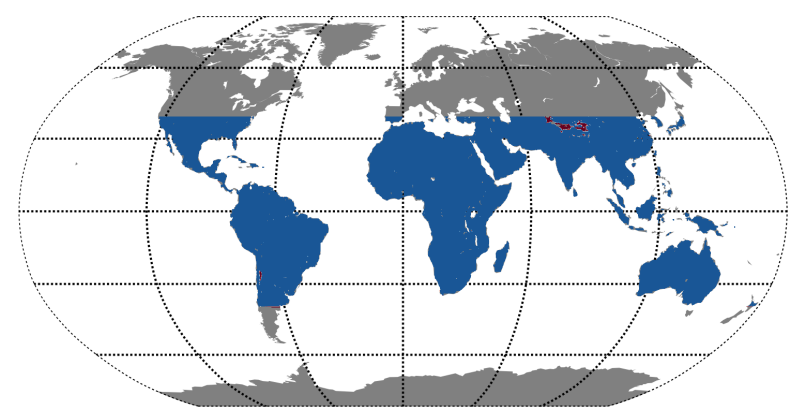

(c) TMI

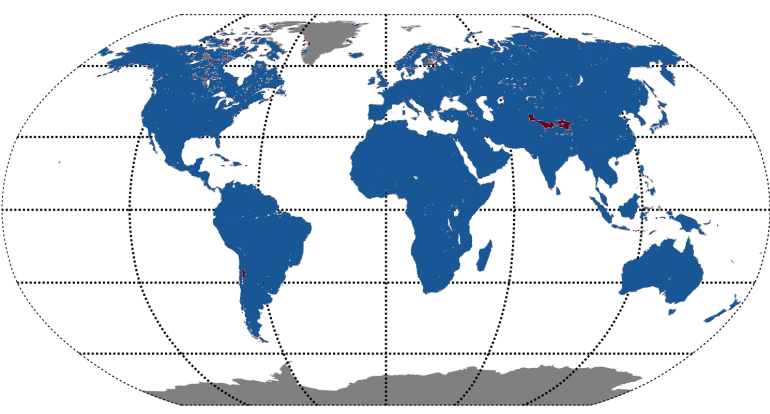

(b) AMSR2

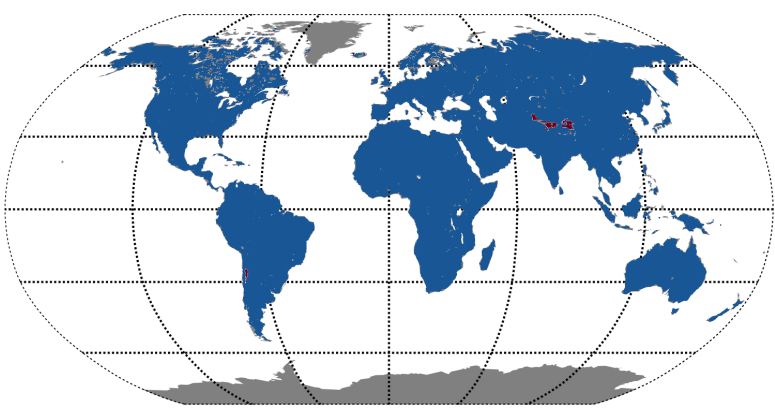

(d) $\mathrm{SSM} / \mathrm{I}$

Figure 9. Ku-band data loss due to failed CDF matching 